\title{
THE USE OF GELATIN CAPSULES IN MOUNTING ORGAN CULTURE EXPLANTS FOR CRYOSTA'T SECTIONING*
}

\author{
Submitted by \\ RICHARD C. KLANN and THEODORE V. FISCHER \\ Department of Anatomy \\ The University of Michigan Medical School \\ Ann Arbor, Michigan 48104
}

I. INTRODUCTION

The use of small pieces of tissue in organ culture presents problems for the histochemist in preparation of these tissues for analysis. A small piece of tissue is susceptible to thawing and refreezing during manipulation after its original rapid freezing. There is also the possibility that the explant might suffer artifactual damage due to pinching, or that it may even be blown away by freon sprays used in quick freezing.

These problems of histochemical technique with small tissue explants have led to a new and much simpler way to assure that the tissue is not disrupted from the time it is taken from culture to the time it is sectioned.

\section{MATERIALS}

Medicinal gelatin capsules, No. 1 Lilly $^{1}$

Embedding matrix (Ames O.C.T. Compound Tissue-Tek), No. 48679-153 VWR ${ }^{2}$

Dewar vacuum flask, $265 \mathrm{cc}$, wide-mouth, No. $63422-040^{2}$

Razor blades, single-edge, No. $48538-005^{2}$

Cryostat, any model attaining a temperature of at least $-20^{\circ} \mathrm{C}$, such as AO Cyro-Cut, No. 48493-020 or Tissue-Tek II, No. 48495$106^{2}$

Microdissecting forceps, No. 6439 Clay Adams $^{3}$

Felt-tipped marking pens (Sanford's Sharpie, black, is the only satisfactory pen) ${ }^{4}$

Hexanes, isomer mixture, No. H-334 Fisher $^{5}$

\section{III.PROCEDURE}

A. Loading capsule with explants

1. Separate clear gelatin capsule into its two parts.

* This investigation was supported by Contract NO1-CP33331 from the National Cancer Institute, National Institutes of Health.

' Eli Lilly Co., Indianapolis, IN.

${ }^{2}$ V.W.R. Scientific, Columbus, OH.

${ }^{3}$ Clay Adams Division of Becton, Dickinson and Co., Parsippany, $\mathrm{NJ}$.

${ }^{4}$ Sanford Corp., Bellwood, IL.

${ }^{5}$ Fisher Scientific Co., Pittsburgh, PA.
2. Apply an identifying mark to the narrower cap with a black fine-tipped felt marker pen.

3. Fill the narrower cap with embedding matrix.

4. Pick up explants, from 1 to $3 \mathrm{~mm}^{3}$ in size, from the organ culture grid with fine-pointed forceps and position them in the cap at the desired depth and orientation.

5. Replace the larger half of the capsule.

6. Rapidly freeze the capsule with its contents in a Dewar flask containing hexane cooled to $-78.5^{\circ} \mathrm{C}$ with dry ice. The capsule remains floating until ready to section.

\section{B. Sectioning of tissue in capsule}

1. When the capsule is to be sectioned, remove it from the hexane and transversely cut it in half with a razor blade.

2. Position the cut side of the part containing the tissue in a small pool of freezing matrix on a cryostat chuck until it is frozen in place. During this procedure the tissue remains frozen because of its position opposite the fluid matrix. 
3. Carefully pare the gelatin away from capsule with a razor blade.

4. Cut cryostat sections at 6 or 8 microns.

5. Lift sections from the knife by touching them with a clean glass cover slip.

6. Dry sections and store frozen until ready for histochemical staining.

\section{DISCUSSION}

In using this method, no thawing and refreezing of explants ever occurred prior to sectioning. Cryostat sections are easily cut and processed for histochemical evaluation.

Somewhat similar methods have been mentioned in the literature but none as simple as this. Fasano and co-workers (1) suggest the use of BEEM capsules and find it necessary to drill holes in dry ice to support them in a chilled state. These translucent BEEM capsules would present some difficulty in the proper positioning of tissue. Since a metal plate is used to initially freeze the tissue before embedding in the capsule, the problems of manipulation of the frozen tissue are still to be encountered. The procedure reported here, on the other hand, owes its simplicity to the fact that all manipulations can be done with the sample frozen within the matrixfilled capsule.

Gelatin capsules can be easily marked for identification of the explant. It is important that a Sharpie black pen be used, since other inks readily dissolve in the hexane coolant. The transparency of the gelatin and of the matrix allows clear visibility while positioning the tissue within the capsule. Orientation and depth in the cap can be precisely controlled. The small fluid volume of the cap permits rapid freezing of the tissue so that destructive large ice crystals will not be formed. When the capsule is reassembled, spilling of matrix is prevented and the air pocket allows the capsule to float in the freezing bath, making retrieval a simple process. Tissue can be stored for considerable time without the fear of desiccation.

Some precautions are necessary to the procedure. Because gelatin is water soluble and the matrix used is an aqueous solution, the capsule begins to get very flexible from ten to fifteen seconds after it is filled. Thus identifying letters should be put on the capsule prior to filling, and rapid handling of the full capsule is important. It is unwise to position the tissue too deeply in the cap since this will place it too near the gelatin. Here it will be less well thermally insulated and may possibly be disturbed when the gelatin is removed.

\section{REFERENCE}

1. Fasano, A.V., P.B. Berendsen, and A. Labriola. 1974. The use of BEEM capsules in the preparation of fresh frozen cryostat sections. Stain Technol. 49: 53-55. 